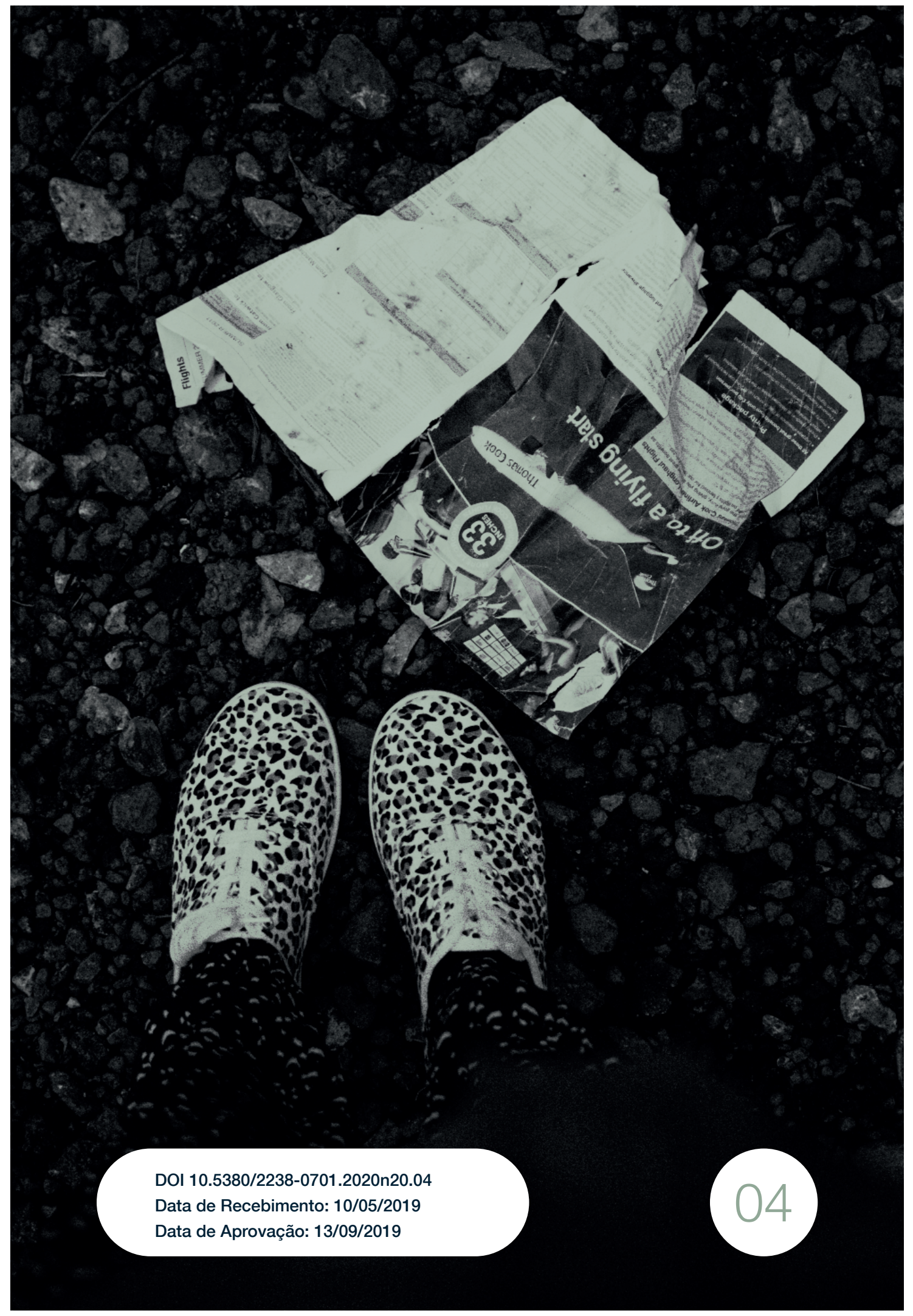


Rural hibrido em sofrimento: mineiridade, mineração e trauma no jornal a sirene 


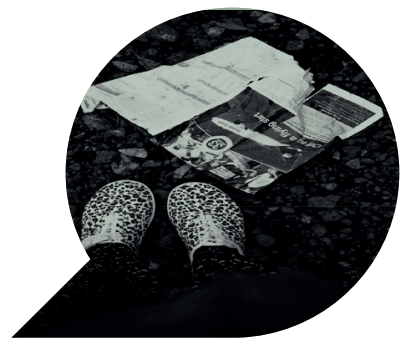

\title{
Rural híbrido em sofrimento: mineiridade, mineração e trauma no jornal $A$ Sirene
}

\author{
Hybrid rural in suffering: mineirity, mining and trauma \\ at The Siren newspaper
}

Rural híbrido en sufrimiento: mineiridade, minería y trauma en el diario La Sirene

\begin{tabular}{c}
\hline JANAÍNA DE OLIVEIRA CAMPOS $^{1}$ \\
\hline RENNAN LANNA MARTINS MAFRA \\
\end{tabular}

Resumo: Este artigo tem como objetivo examinar as configurações de sentido sobre mineração, mineiridade e ruralidade presentes no jornal $A$ Sirene - publicação mensal elaborada na perspectiva dos sujeitos atingidos pela tragédia ambiental de Mariana (2015). Para isso, foram analisadas narrativas jornalísticas de trauma e sofrimento presentes no jornal. Como proposta metodológica, foi utilizada a análise de paisagens textuais (textos verbo-visuais), de Gonzalo Abril (2012). Como principais resultados, identifica-se que a emergência da tragédia provoca, nas narrativas, esforços em demonstrar um rural perdido, pautado por traços de uma mineiridade que, em outros tempos, encobriu os conflitos

1 Graduada em Jomalismo pela Universidade Federal de Viçosa e Mestre em Extensão Rural pela mesma universidade.

2 Professor do Departamento de Comunicação Social e do Programa de Pós-Graduação em Educação. 
da mineração em Minas Gerais. Além disso, foi possível identificar que o jornal $A$ Sirene evidenciou, com as narrativas construídas, fortes traços de um rural híbrido, em sofrimento.

Palavras-chave: Jornalismo; Sofrimento; Trauma; Rural; Tragédia de Mariana.

Abstract: This paper aims to examine the sense configurations of meaning about mineirity, mining and rurality present in the newspaper The Siren - monthly publication elaborated from the perspective of the subjects affected by Mariana's environmental tragedy (2015). For that, journalistic narratives of trauma and suffering present in the newspaper were analyzed. As a methodological proposal, we used the textual landscapes analysis (verbal-visual texts), by Gonzalo Abril (2012). As the main results, it is identified that the emergence of tragedy provokes efforts in the narratives to demonstrate a lost rural, based on the characteristics of a mineirity that in the past covered the conflicts of Minas Gerais State. In addition, it was possible to identify that the newspaper The Siren demonstrated, with the constructed narratives, strong traces of a rural hybrid, in suffering.

Keywords: Journalism; Suffering; Trauma; Rural; Tragedy of Mariana.

Resumen: Este artículo tiene como objetivo examinar las configuraciones de sentido sobre mineiridade, minería y ruralidad presentes en el periódico A Sirene - publicación mensual elaborada en la perspectiva de los sujetos afectados por la tragedia ambiental de Mariana (2015). Para ello, se analizaron narrativas periodísticas de trauma y sufrimiento presentes en el periódico. Como propuesta metodológica, se utilizó el análisis de paisajes textuales (textos verbo-visuales), de Gonzalo Abril (2012). Como principales resultados, se identifica que la emergencia de la tragedia provoca, en las narrativas, esfuerzos en demostrar un rural perdido, pautado por rasgos de una minería que, en otros tiempos, encubrió los conflictos de la minería en Minas Gerais. Además, fue posible identificar que el diario La Sirene evidenció, con las narrativas 
construidas, fuertes rasgos de un rural híbrido, en sufrimiento.

Palabras clave: Periodismo; sufrimiento; traumatismos; rural; tragedia de Mariana.

\section{Introdução}

Este artigo tem como proposta principal investigar as configurações de sentido sobre mineração, mineiridade e ruralidade, presentes no jornal $A$ Sirene, em meio a um contexto rural - as localidades de Bento Rodrigues e Paracatu de Baixo, pertencentes à cidade de Mariana (MG) -, afetado por um acontecimento - o rompimento de uma barragem de minérios - a barragem de Fundão - no dia 05 de novembro de 2015, causador de uma tragédia de proporções ainda desconhecidas. De modo mais específico, interessa-nos investigar como o sofrimento provocado pela tragédia e pautado no jornal foi capaz de evidenciar nuances e traços dos contextos rurais afetados por tal rompimento, notadamente, enredados numa relação discursiva com sentidos sobre mineiridade e sobre a própria mineração, para muito além de sentidos que emergiram publicamente como parte das consequências contemporâneas provocadas pela tragédia.

O jornal A Sirene é uma publicação produzida de maneira colaborativa pelo coletivo "Um Minuto de Sirene", formado por moradores da região afetados pela tragédia e que surgiu em parceria com o projeto de extensão da Universidade Federal de Ouro Preto (UFOP), "Nos Bastidores da Notícia", direcionado a crianças e adolescentes de bairros periféricos da cidade de Mariana/MG e região. O jornal foi lançado em fevereiro de 2016 e, desde então, é publicado mensalmente (com exceção do mês de maio de 2016). Possui em torno de 16 páginas por edição, excluindo o exemplar de um ano da tragédia (novembro de 2016), que trouxe uma cobertura especial com 32 páginas, e a edição de um ano de jornal (dois anos de tragédia), também com 32 páginas. Sua tiragem é de dois mil exemplares e conta também com uma página no Facebook ${ }^{3}$, um blog ${ }^{4}$ e um portal por meio do qual é possível acessar as

3 https://www.facebook.com/JornalSirene/?fref=ts

4 https://jornalasirene.wordpress.com/ 
edições do jornal $\left.\right|^{5}$.

Para identificarmos os traços dos contextos rurais afetados pelo rompimento da barragem, presentes nas narrativas jornalísticas, adotamos a proposta metodológica de análise de textos verbo-visuais, de Gonzalo Abril (2007; 2012). Trata-se de uma vertente da análise de conteúdo que aborda a relação entre texto e ambiente, baseada no conceito de paisagens textuais. Segundo Vianna e Vaz et al. (2015), "paisagem significa a porção de uma área cujos sentidos da percepção de quem a observa consegue ver, escutar e sentir e alcançar de um determinado ponto de vista" (p. 2). A metodologia é também discutida por Carl Sauer (1998 apud Vianna e Vaz et al. 2015), que aponta paisagem como "associação distinta de formas, ao mesmo tempo físicas e culturais".

Por essa perspectiva, os textos formam unidades que se articulam para constituir sentido(s). A unidade do texto constituiria um relevo integrante de uma paisagem, esta que faz parte de um ambiente ainda maior, uma espécie de "superfície contextual" que acolhe e abarca os relevos na constituição dos sentidos a serem explorados pelos leitores/ ouvintes. Segundo Vianna e Vaz et al. (2015), "o leitor/ouvinte integra a paisagem com a sua presença, ainda que silenciosamente, e, ao mesmo tempo, mobiliza sua consciência, experiência, estética e moral ao observá-la" (p. 5).

Tavares (2016), baseando-se em Abril (2012), ressalta que a análise é feita em totalidade, ou seja, sem fragmentar o objeto em partes menores de significação. A autora demonstra que a análise de Abril (2012), refutando um gesto que insiste em buscar o que os textos verbo-visuais supostamente significariam em si mesmos, propõe entender de que forma são atribuídos sentidos a tais textos, por meio de uma metodologia visual que analisa, além dos elementos visíveis, também as práticas sociais e as relações de poder presentes. Analisamos o jornal A Sirene seguindo a perspectiva de Abril $(2007$; 2012) no que diz respeito a tentar

\footnotetext{
5 As edições do Jornal A Sirene podem ser consultadas no endereço eletrônico www. issuu.com/jornalasirene. A partir de informações atualizadas em setembro de 2019, até este ano foram publicadas 39 edições do jornal, sendo que a última edição até esta data foi publicada em junho de 2019. Além disso, cabe destacar que a edição do jornal do mês de março de 2019 - a de número 36 - ampliou o escopo de discussões da publicação ao tratar da tragédia ambiental de Brumadinho, ocorrida em janeiro de 2019, em função do rompimento da Barragem do Córrego do Feijão, gerida pela empresa mineradora multinacional Vale S. A - tragédia de proporções ainda desconhecidas, provocando a morte identificada de 259 pessoas, sendo que 13 ainda se encontram desaparecidas (fonte: https://g1.globo.com/ mg/minas-gerais/noticia/2019/01/26/veja-quem-sao-as-vitimas-da-tragedia-em-brumadinho.ghtml $<$ Acesso em 25 de maio de 2020>).
} 
enxergar, em meio às narrativas jornalísticas produzidas, elementos de um contexto sociohistoricocultural que engloba, precede e sucede as próprias narrativas.

Partindo de tais pressupostos, foram selecionadas todas as edições do Jornal A Sirene no espaço de um ano, a partir de sua primeira edição, lançada em fevereiro de 2016, até a edição de fevereiro de 2017. Neste período, foi possível acompanhar as reverberações do acontecimento, as inquietações que ele propôs e as configurações de sentido sobre mineração, mineiridade e ruralidade assumidas pelos sujeitos afetados, na medida em que novas relações com o espaço, com o trabalho e com o tempo emergiram.

\section{Jornalismo e lógicas de sofrimento: a expressão do trauma na tragédia}

O jornalismo se caracteriza por ser um tipo de linguagem social que é essencial na atualidade, já que, como premissa, atua na compreensão do presente. Nesse sentido, sua relação com o acontecimento - tomado como algo que introduz uma novidade, um corte, uma fissura - faz-se pela construção de narrativas, na forma de notícias. Por meio dessas narrativas, de acordo com Barbosa e Carvalho (2017), são criadas esferas públicas de memória real. O jornalismo, então, caracteriza-se como modalidade narrativa do presente e "auxilia no processo de normalização do evento traumático” (BARBOSA; CARVALHO, 2017, p. 23).

O sofrimento é combustível para as mídias, em especial para os contextos jornalísticos, estes que buscam suscitar questões políticas e evidenciar situações de injustiça. De acordo com Cal e Lage (2015), as narrativas jornalísticas orientam um sentimento de afinidade em relação ao fato noticiado, ao apresentar indivíduos dispostos nas franjas de um real em movimento:

A inserção de indivíduos concretos com suas histórias pessoais transforma o clamor generalista e impessoal próprio da piedade em uma demanda por compaixão. Nesse sentido, a retórica da piedade cederia lugar a uma nova retórica, a da produção da "vítima virtual", cuidadosamente identificada e singularizada (CAL; LAGE, 2015, p. 148). 
Para Silva (2017, p. 18), os eventos traumáticos noticiados servem às vítimas, cuja "exposição implica potencialmente o advento da comoção, seguida da solidariedade e de apoio em causa e recursos, bem como de providências do poder público, em reparo e prevenção de desastres futuros" (SILVA, 2017, p. 18). Como o trauma pode ser caracterizado como uma "memória de um passado que persiste - insiste em não passar - e que, portanto, desordena a estrutura temporal do sujeito afetado por ele" (BARBOSA; CARVALHO, 2017, p. 21), o jornalismo atua como forma de evidenciar a reinserção da vítima, perante à sociedade e, em última análise, à vida. Essa inserção ocorre, de acordo com Barbosa e Carvalho (2017), devido à simbolização criada a partir das formas de narrativas: linearidade, repetições e construções metafóricas. Além das características jornalísticas, os autores também apontam que o relato traumático contribui para retemporizar o presente e aproximar o afetado da realidade comum. Nesse sentido, o jornal impresso, enquanto veículo portador desse sofrimento, apresenta, de acordo com Cal e Lage (2015),

a aparição do sofrimento como elemento decorrente de um contexto social específico, evidenciando uma problemática política a partir da exposição do infortúnio alheio; e a aparição desses sujeitos sob o viés da exemplaridade, como indivíduos cuja história é, na verdade, a história de outros semelhantes - e, por sua vez, seu sofrimento é correlativo ao de outros sujeitos (CAL; LAGE, 2015, p. 146).

O relato jornalístico do sofrimento coloca o sujeito afetado como narrador extraordinário de fatos e, por isso, portador da verdade, como apontam Barbosa e Carvalho (2017). Tais autores, que também pesquisaram a Tragédia de Mariana, evidenciam que, neste caso, houve a emergência de sinais de uma identidade distante do presente munida de alguns rastros do passado, estes que só foram acionados no momento do trauma. Entretanto, aqui vale ressaltar que o jornalismo não explica o sofrimento: ele o presentifica, a partir de uma interpretação (hermenêutica) que faz com que o trauma esteja presente. É em meio à presença que, de acordo com Mafra (2011), os sujeitos podem afetar-se mutuamente, lançando mão de suas experiências anteriores para criar uma nova. No caso do jornal A Sirene, seu surgimento inevitavelmente vincula-se à própria presença da atividade mineradora em meio aos contextos rurais mais proximamente afetados pelos dejetos do rompimento 
(Paracatu de Baixo e Bento Rodrigues). É assim que jornal A Sirene presentifica o próprio contexto de um rural híbrido, afetado historicamente pela mineração, como será visto a seguir.

\section{Mineração na região de Mariana: a configuração histórica de um rural híbrido}

A mineração no estado de Minas Gerais remonta ao período chamado Ciclo do Ouro, iniciado no século XVII e foi responsável por impulsionar a criação de diversas cidades no interior e a transferência de sede da Coroa Portuguesa de Salvador para o Rio de Janeiro (SILVA, 1995). Com o passar dos anos e a queda da extração do ouro, exploradores perceberam que Minas Gerais era uma região também rica em diversos outros recursos, como diamantes, pedras preciosas e minério de ferro.

Especificamente sobre a região de Bento Rodrigues, relatos feitos pelos moradores no jornal A Sirene (edição 0, p. 7) dão conta de que a mineração na região teve início por volta de 1697, quando bandeirantes, insatisfeitos com as condições da exploração do ouro nas cidades de Ouro Preto e Mariana, resolveram explorar regiões circunvizinhas. Foi nesta ocasião que o explorador Bento Rodrigues fundou a comunidade com seu próprio nome. De maneira geral, o relato mostra que a comunidade sempre esteve ligada à exploração mineral e que, em algum momento, teve a agricultura como suporte referente ao abastecimento de insumos alimentícios às caravanas que chegavam ao local para minerar.

Por conta disso, sujeitos ligados às regiões rurais afetadas mais diretamente pela tragédia de Mariana (2015), ao apresentarem a mineração como principal particularidade no que se refere à configuração histórica de seus espaços rurais, nos dão pistas para inferir como tais lugares têm sido historicamente atravessados, desde os primórdios do Brasil colônia, pelo amplo processo de globalização do capital. Assim, é possível entender que, ao inserir este rural em fluxos e circulações mundiais, a globalização fez emergir, em tais cenários, ambientes marcados pelo hibridismo cultural.

De modo mais específico, o hibridismo pode ser entendido como um fenômeno que redefine o senso de pertencimento e de identidade, "organizado cada vez menos por lealdades locais ou nacionais e mais 
pela participação em comunidades transnacionais ou desterritorializadas de consumidores" (Canclini, 1998, p. 52). O autor também salienta que as identidades locais não desaparecem, sendo reconfiguradas e/ou adaptadas, podendo, ainda, ganhar destaque entre culturas globalizadas como uma forma de resistência. De maneira geral, Canclini (1998) insere a questão do hibridismo na globalização, entendida por ele como um intercâmbio entre territórios, não necessariamente causador de uma homogeneização, mas provocador de rupturas e negociações.

Em meio aos contextos rurais, o hibridismo é caraterizado, de acordo com Rua (2005), como um fenômeno que, de algum modo, incorpora elementos do urbano, mas que interage com ele e cria novas relações de ruralidade. Dessa forma, a hibridização dos espaços rurais e urbanos, ou seja, a junção de formas e conteúdos no mesmo espaço, faz com que, segundo Martins e Souza (2010), haja um encontro de estágios de interação com o ambiente. Para os autores, estes espaços não são extintos, mas, sim, recriados para dar conta de compreender essa nova configuração identitária. Resumidamente, seria "um rural que interage com o urbano, sem deixar de ser rural" (MARTINS; SOUZA, 2010, p. 48). Assim, há cada vez mais diversidade de realidades possíveis, o que inclui a construção do que os autores chamam de novas ruralidades e novas urbanidades, em que cidade e campo se entrecruzam de maneira simbólica6.

Essa nova interação rural-urbano é o que Rua (2005) também cha-

6 Com relação a essas discussões, cabe destacar que o termo ruralidade possui diversas possibilidades interpretativas, para além da noção assumida, neste trabalho, a partir das concepções de Rua (2005) (quais sejam, as que tomam a ruralidade como modos de vida hibridizados com modos de vida urbanos). Um fato bastante contundente é que a ruralidade possui notável correlação com uma espécie de antônimo - a urbanidade. Superando muitas visões do senso comum que tomam o rural como atrasado e o urbano como desenvolvido, e pensando em outras abordagens possíveis, destacamos: a) a noção de Veiga (2004), que toma a ruralidade como um conjunto de relações sociais, estas que, de algum modo, nunca se resumiram às atividades agropecuárias, mas sempre estiveram em interação, de um modo mais ou menos intenso, com os espaços urbanos; aqui, é inevitável tomar o rural como espaço mais próximo de um ambiente não modificado materialmente pela experiência humana - o que se costuma chamar de "natureza", portadora de outras temporalidades e espacialidades; b) o trabalho de Braga et al. (2015), autores que se esforçam por apresentarem o que seria um índice de urbanidade e ruralidade, segundo o qual, através dos modos de vida dos sujeitos, é possível perceber as novas formas de ruralidade ou urbanidade; c) os estudos de Carneiro (1998), com um viés voltado aos processos culturais e identitários tributários da relação e dos tensionamentos entre contextos rurais e urbanos. Dentre muitos outros caminhos possíveis para apreender-se tal discussão, é válido, por fim, destacar que a ruralidade não se restringe ao caso particular de Minas Gerais e à identidade mineira - o que se observa nesses territórios é uma espécie de configuração sociohistórica e singular de sentidos que se dá, de modo distinto, de outros territórios rurais brasileiros. 
ma de ressignificação dos espaços. Para o autor, essa condição é produto desse novo conjunto de relações que deixam de ser explicadas apenas pelas divisões tradicionais estabelecidas entre urbano e rural. Assim, uma noção de rural híbrido tenta ultrapassar essa dualidade ao revelar a multiplicidade de papéis e formas de interação que emergem junto aos espaços rurais. O estudo desse hibridismo é importante para entender os sujeitos afetados pela Tragédia de Mariana - sujeitos estes que expressam seus sofrimentos, frutos de condições e experiências híbridas. Junto a isso, nos contextos de Minas Gerais, sociohistoricamente pautados pela presença da mineração, cabe questionar em que medida traços de sua ruralidade, para além do hibridismo cultural, também se relacionam com marcas identitárias de uma mineração, forjada por determinados grupos sociais para esconder e tentar diluir conflitos, como posto a seguir.

\section{A ruralidade como dispositivo para encobrir a mineração: a configuração da mineiridade}

A cultura regional do estado de Minas Gerais se formou essencialmente no período da mineração e, de acordo com Dias (1985), a instalação deste sistema econômico promoveu considerável diferenciação no espaço jurídico-institucional do Brasil colônia (até então, fortemente agrário), o que resultou em urbanização precoce, miscigenação populacional e estratificação social. De tal sorte, durante o período da mineração, relatos indicavam supostas características comuns ao sujeito habitante da região central de Minas Gerais (onde se concentrava tal atividade): devido às suas condições de trabalho nas minas e às dinâmicas sociais, o "mineiro" foi apontado, incialmente, como aquele que trabalha em silêncio e é desconfiado (REIS, 2007).

Tal denominação, no entanto, não dava conta de atender aos anseios políticos de uma elite que, no século XX, almejava o poder no cenário nacional. Para isso, o discurso regionalista mineiro passou a utilizar-se de uma suposta capacidade de reorganizar os fatos sociais para gerar alterações no discurso da identidade mineira (REIS, 2007). Uma das razões que impulsionou esta mudança foi a transferência da capital do estado para Belo Horizonte. A cidade representava um marco na 
identidade de Minas Gerais, relegando a Ouro Preto, antiga capital, o papel de guardar as histórias do mineiro das minas de ouro em meio a todo o passado glorioso da cidade (REIS, 2007).

Paralelamente, neste período, Minas perdeu o posto de Estado mais populoso para São Paulo e também ampliou suas atividades econômicas, investindo na agricultura. No entanto, esta mudança, de acordo com Leal e Oliveira (2014), carrega também um sentido simbólico para a identidade mineira, já que, de acordo com os autores, "a mineração envolve fatores como a aventura (perigo e descobertas), mobilidade (busca de novas lavras) e insegurança (física e financeira)" (LEAL; OLIVEIRA, 2014, p. 9), características que não eram interessantes de ser exaltadas na disputa política no contexto da República Velha. Por outro lado, "as atividades agrícolas remetem ao contrário - estabilidade, segurança e tranquilidade" (LEAL; OLIVEIRA, 2014, p.9). Isso fez com que elites mineiras repensassem a forma de atuação no campo da política nacional - de contestadores e rebeldes (remetendo, sobretudo, à Inconfidência Mineira) passando a conciliadores, os que buscam a integração.

Por conta disso, na visão de Reis (2007), a mineiridade, identidade forjada do sujeito mineiro, foi criada por determinados grupos de poder: características referentes ao ser mineiro começaram a ser projetadas como um padrão socialmente constituído, com o claro objetivo de ignorar/eliminar conflitos (ROCHA, 2003). A mineiridade pode então ser definida como um conjunto de valores e características atribuído aos mineiros: "trata-se de uma construção discursiva vinculada à concepção de uma regionalidade, que é definida por certas peculiaridades históricas, econômicas e sociais" (LYSARDO-DIAS, 2008, p. 3). Rocha (2003) acrescenta que a mineiridade também envolve apego à tradição, valorização da ordem, prudência, aversão a posições extremistas, revelando o suposto traço conciliador dos mineiros e as presumíveis habilidade e paciência como estratégias para lidar com questões políticas.

Com isso, é possível perceber que o discurso da mineiridade prolonga uma tradição cultural do estado em abordar o rural como marca identitária. Para França (1998), há uma aura em torno do próprio nome do estado, que acaba por englobar as montanhas, os casos mineiros, a história ou mesmo o comportamento "normal" do mineiro associado à tradição, constituindo a "alma mineira" (p.69), aspecto este que encontra 
no jeito e atitude do seu povo a sua forma de expressão. Para França (1998), a representação do ser mineiro está muito ligada a saudosismo, misticismo e onirismos. Conforme Ângelo (2005), a mineiridade também está associada a elementos como a pacatez, a vida rural e a morosidade, além de outras, como a habilidade política e a capacidade de articulação (na moderação e no equilíbrio), compondo características presentes na mineiridade.

Vale ressaltar, sobretudo, que, apesar de o mineiro "tido como típico" ser originário das regiões mineradoras, tais características não aparecem como sendo marcas de sua identidade. O que se evidencia, na visão de autores como França (1998), Rocha (2003), Ângelo (2005) e Reis (2007), é que a ruralidade, representada pelo apelo à natureza e pelo jeito tímido do mineiro, aparece como um distintivo forjado discursivamente para projetar o Estado como um todo, e como eficiente dispositivo relacional, voltado tanto a esconder os conflitos históricos da mineração, ironicamente estampados na própria enunciação de seu nome, quanto a servir como estratégia discursiva às elites políticas de Minas Gerais, em direção a disputas de poder no cenário nacional.

$\mathrm{Na}$ contemporaneidade, a mineiridade continuaria ainda eficiente, de um ponto de vista discursivo, para esconder os conflitos da mineração presentes historicamente nos cenários rurais híbridos do Estado - mesmo com a fissura pública de um trauma, como a tragédia de Mariana? Por tudo isso, é nosso esforço, nos dois próximos tópicos, compreender quais configurações de sentido foram mobilizadas no jornal A Sirene, referentes à mineiridade, ruralidade e mineração, a partir do trauma causado pela tragédia - evidenciado e narrativamente presentificado no jornal. Analisaremos as reportagens como paisagens textuais, ou seja, no conjunto formado por espaço visual (texto e imagem) e espaço interpretativo-contextual, conforme proposto por Abril (2007; 2012).

\section{Mineiridade: a mobilização de um rural híbrido no jornal $A$ Si- rene}

Em linhas gerais, é possível perceber, inicialmente, que a mineiridade evidenciada nas matérias publicadas pelo jornal $A$ Sirene aparece configurada em relação a um saudosismo de uma vivência rural que, 
historicamente, não fazia parte das experiências dos sujeitos da região afetada pela tragédia. Como vimos anteriormente, as regiões rurais afetadas já nasceram como parte de um hibridismo decorrente da globalizada atividade da mineração. Entretanto, no momento do trauma sofrido, os sujeitos afetados parecem valer-se de uma mineiridade imaginada, apeladora a um saudosismo rural que, de fato, não parecia ser hegemonicamente experienciado por eles.

No texto intitulado "Projetando a Esperança" da edição número 2 (figura 1) há, por exemplo, uma busca por elementos que fazem parte de uma suposta identidade perdida por estes sujeitos, como o quintal, o queijo e o café. Além disso, a imagem constrói a noção de um rural perdido, aliado a uma atmosfera supostamente "típica de uma mineiridade", apostando numa referência à uma paisagem natural composta por animais pastando livremente - referências estas da suposta tranquilidade, calma, ordem, de uma mineiridade pacata e inofensiva. Dito por outras palavras, a presença da imagem junto ao texto estabelece uma espécie de convite para o leitor adentrar naquela casa e partilhar da identidade mineira projetada.

Figura 1: Projetando a esperança, 2016, Edição 2 do Jornal A Sirene.

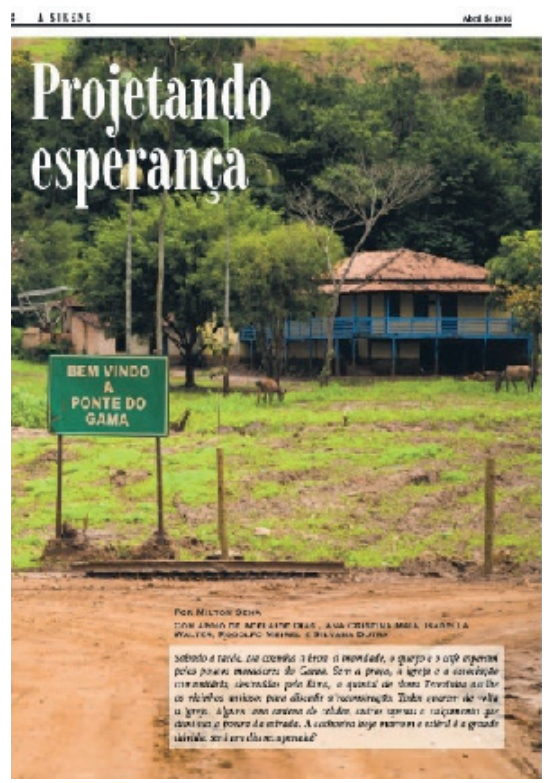


Essa referência ao rural que nunca existiu fica visível quando, ao analisarmos os modos de vida presentes nos relatos contidos no jornal, percebemos que estes apresentavam marcas identitárias predominantemente urbanas - como é possível de notar-se na matéria publicada na edição de número 5, "Mãos que não querem parar" (figura 2). Nesta reportagem, são apresentadas pessoas que perderam suas profissões com a tragédia. Com exceção do primeiro entrevistado (que é apicultor), as demais profissões são tipicamente urbanas: o jornal apresenta Iracema, que é dona de sorveteria; Valéria, que atua como cabelereira; comerciantes da cidade de Barra Longa (município próximo às localidades de Bento Rodrigues e Paracatu de Baixo, também afetado pela lama). Nesse sentido, apesar de estes sujeitos estarem inseridos em uma comunidade considerada rural e, ainda, fazerem constantemente referência a este suposto rural que perderam, estamos, de fato, diante de um rural que se apresenta notadamente híbrido.

Figura 2: Mãos que não querem parar, 2016, Edição 5 do Jornal A Sirene.

4 num intess

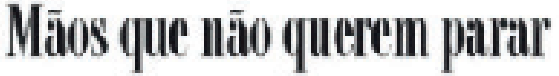

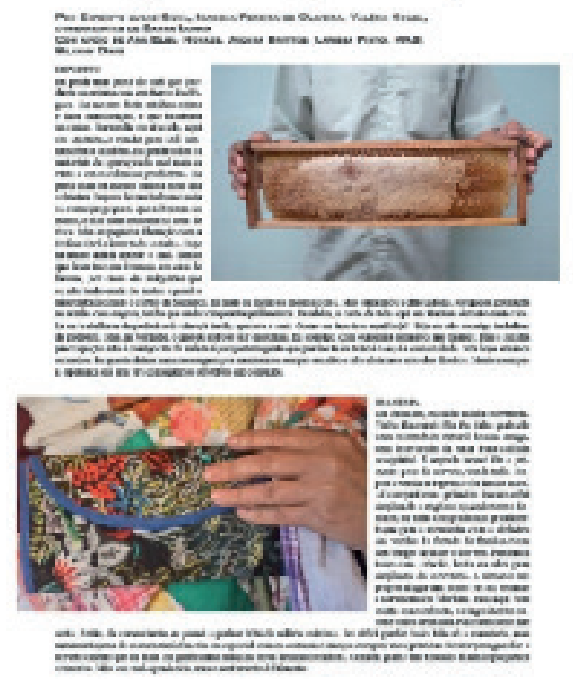

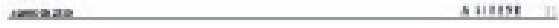

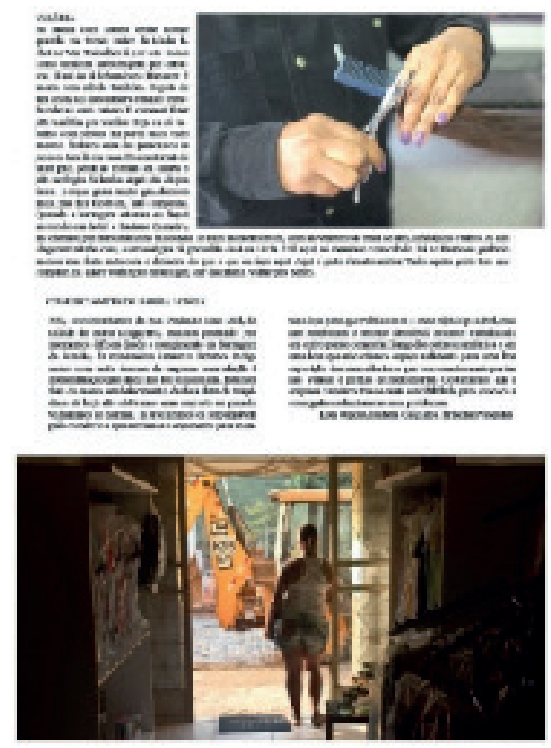

Como o hibridismo é parte da globalização, gesto que, ao mesmo tempo, mescla culturas e encurta as distâncias espaciais e temporais, 
tal fenômeno acaba por colocar à margem um conjunto de sujeitos não implicados em contextos hegemônicos (Canclini, 1998). Com isso, os moradores de Bento Rodrigues e das demais comunidades atingidas, apesar de estarem imersos em um contexto de urbanização, promovido em grande parte pela mineração na região, parecem ter sido historicamente negligenciados e ainda permanecem excluídos de outros contextos híbridos da globalização.

Assim, em algumas publicações do jornal, os moradores (inclusive as crianças) relatam preconceitos sofridos ao chegarem à cidade de Mariana - sobretudo para habitarem residências provisórias após terem suas casas perdidas. Com relação a isso, duas matérias se destacam. A primeira delas, cujo título é "Diversidade que nos convida a acolher", da edição de número 6 (figura 3), trata do sofrimento dos moradores ao lidarem com o trauma da perda do lugar em que viviam e dos desafios de começarem uma vida nova, próximos a julgamentos proferidos pelos moradores da cidade.

Figura 3: Mãos que convidam a acolher, 2016, Edição 6 do Jornal A Sirene.

\section{Diversidade que nos convida a acolher}

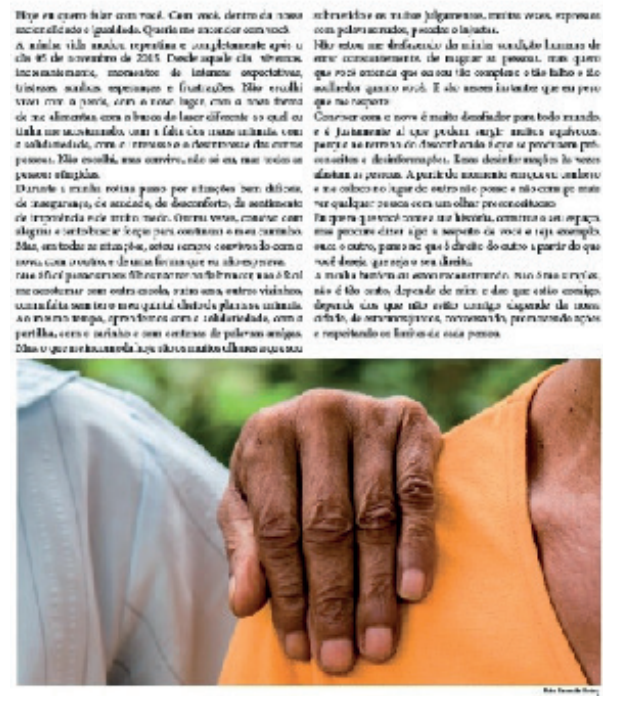


Já na segunda matéria de título "Era uma vez", da edição 9 (figura 4), uma moradora atingida retrata o sofrimento vivenciado pelos atingidos a partir da apresentação de teatro de bonecos. Nesta história, ela relata como foi o processo de mudança, incluindo uma espécie de perda de identidade, junto à ausência de uma sensação de pertencimento ao novo contexto pós-tragédia. Durante o texto, são evidenciados alguns estigmas que mostram dificuldades de aceitação dos moradores da cidade de Mariana em relação aos atingidos. Chama-nos atenção também o fato de que a autora evidencia que as crianças estão sendo chamadas de "pé de lama" e que alguns moradores da cidade de Mariana teriam chegado, supostamente, a desejar a morte de quem foi atingido pela tragédia.

Figura 4: Era uma vez 2016, Edição 9 do Jornal A Sirene.

10 A SIREN

Jezton $1: 2 u$

\section{Era uma vez}

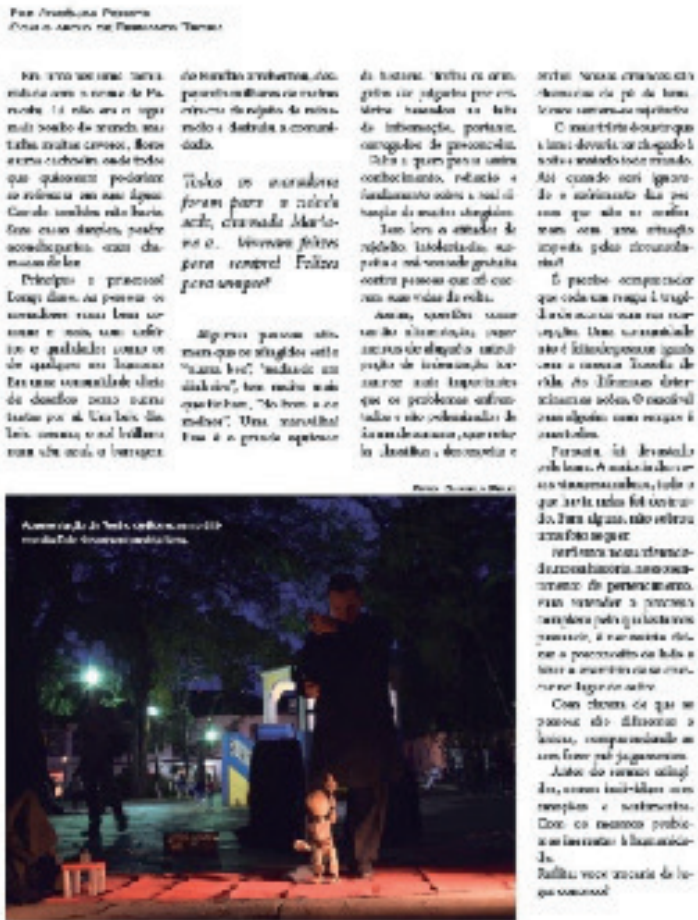


Sendo assim, o que percebemos, em linhas gerais, é que sentidos de mineiridade foram mobilizados como tentativas de construção de uma ruralidade supostamente perdida, mas não vivenciada, nas experiências híbridas dos sujeitos, antes da tragédia. Dito por outras palavras, quando a mineiridade foi mobilizada pelo jornal, não houve uma problematização da própria relação histórica entre o rural e a mineração - uma vez que os sujeitos atingidos são originários de um espaço em que o rural híbrido gerou, além de todo o trauma presente, um sofrimento que ressoa, fruto de um processo histórico de exclusão. Assim, a própria não observância da relação visceral de suas experiências sociais anteriores à tragédia como parte de um rural híbrido tende a diminuir a própria potência política do grupo, na reivindicação de seus direitos.

Por outro lado, longe de culpabilizá-los, a própria configuração de um rural híbrido acaba dificultando a construção de uma pauta identitária menos fluida: tais sujeitos parecem encontrar-se numa espécie de limbo identitário e acabam tentando lançar mão de uma suposta mineiridade como estratégia de evidenciação de um lugar perdido que eles mesmos não experimentavam. Assim, a eficiente estratégia discursiva da mineiridade, mesmo diante de uma tragédia sem limites, parece continuar efetiva para esconder a relação histórica que o rompimento da barragem possui com a própria constituição de uma identidade regional, forjada em Minas Gerais. Entretanto, ainda que não problematizada a própria mineiridade, um rural híbrido em sofrimento aparece como central nas produções do jornal $A$ Sirene, como veremos a seguir.

\section{Tragédia em Mariana: sofrimento e trauma no jornal A Sirene}

O jornal A Sirene nasce, antes de tudo, com o propósito de evidenciar o trauma sofrido pelos atingidos: seu próprio nome faz referência à sirene, dispositivo sonoro de segurança que não tocou para avisar aos moradores da região sobre o rompimento da barragem. Assim, o rural híbrido perdido por esses sujeitos atingidos, ainda que não tenha sido problematizado, é mobilizado, e sua relação histórica com a mineração, ainda que não explicitada argumentativamente, não consegue ficar totalmente escondida.

Essa relação histórica pode ser percebida na matéria "Seu Filo- 
meno me contou", da edição de número 0, (figura 5), que trata da narrativa de como a mineração chegou na comunidade de Bento Rodrigues, em 1697. Ao longo do texto é possível observar todas as consequências sociais e políticas com a chegada da atividade mineradora naquela região. Nas imagens, é possível perceber vestígios históricos daquela época e vislumbrar a situação de devastação em que Bento Rodrigues se encontra após a tragédia. De algum modo, o jornal demonstra que a mineração é causadora do trauma e do sofrimento, onde quer que tal atividade teime em existir.

Figura 5: Seu Filomeno me contou, 2016, Edição 0 do Jornal A Sirene.

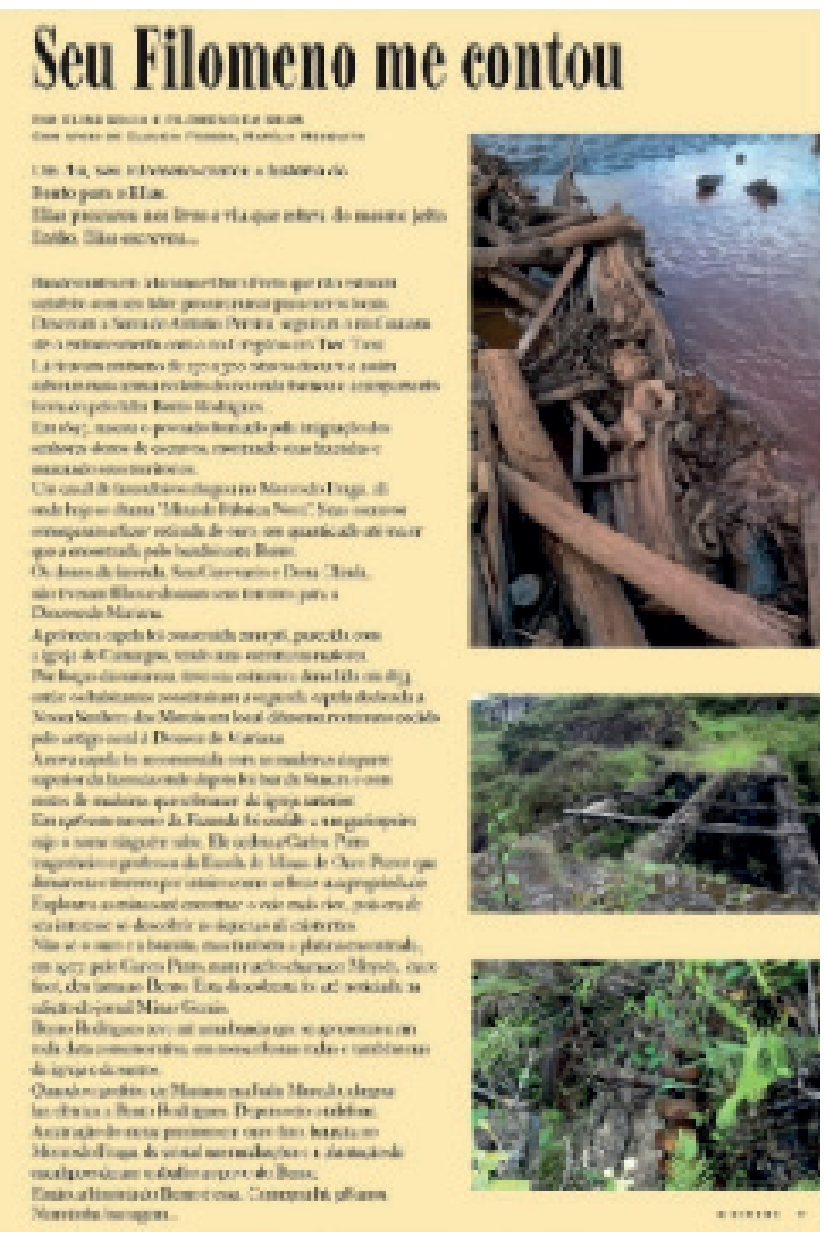


Ainda no que diz respeito ao sofrimento decorrente da atividade mineradora, percebe-se que algumas histórias sempre se repetem nas áreas em que há tal exploração. Um exemplo da indignação com a atividade mineradora é o texto intitulado "Dique S4 - Problema ou solução", da edição 05 (figura 6). Nesta reportagem, é abordada a construção de um novo dique para conter os rejeitos que sobraram da tragédia. Entretanto, mais do que expor simplesmente o processo de construção de uma barragem, o texto evidencia uma relação de causalidade presente em qualquer atividade mineradora: alagamento de casas, presença de ruínas, ausência de histórias. Aqui, além de um passado, um futuro também é projetado: de acordo com o autor do texto, a própria mineração não é capaz de sustentar os discursos de promessa de ressarcimento ofertados pela empresa Samarco no momento pós-tragédia, uma vez que, da terra destruída, os atingidos nunca serão ressarcidos.

Figura 6: Dique S4- Problema ou solução?, 2016, Edição 5 do Jornal A Sirene.

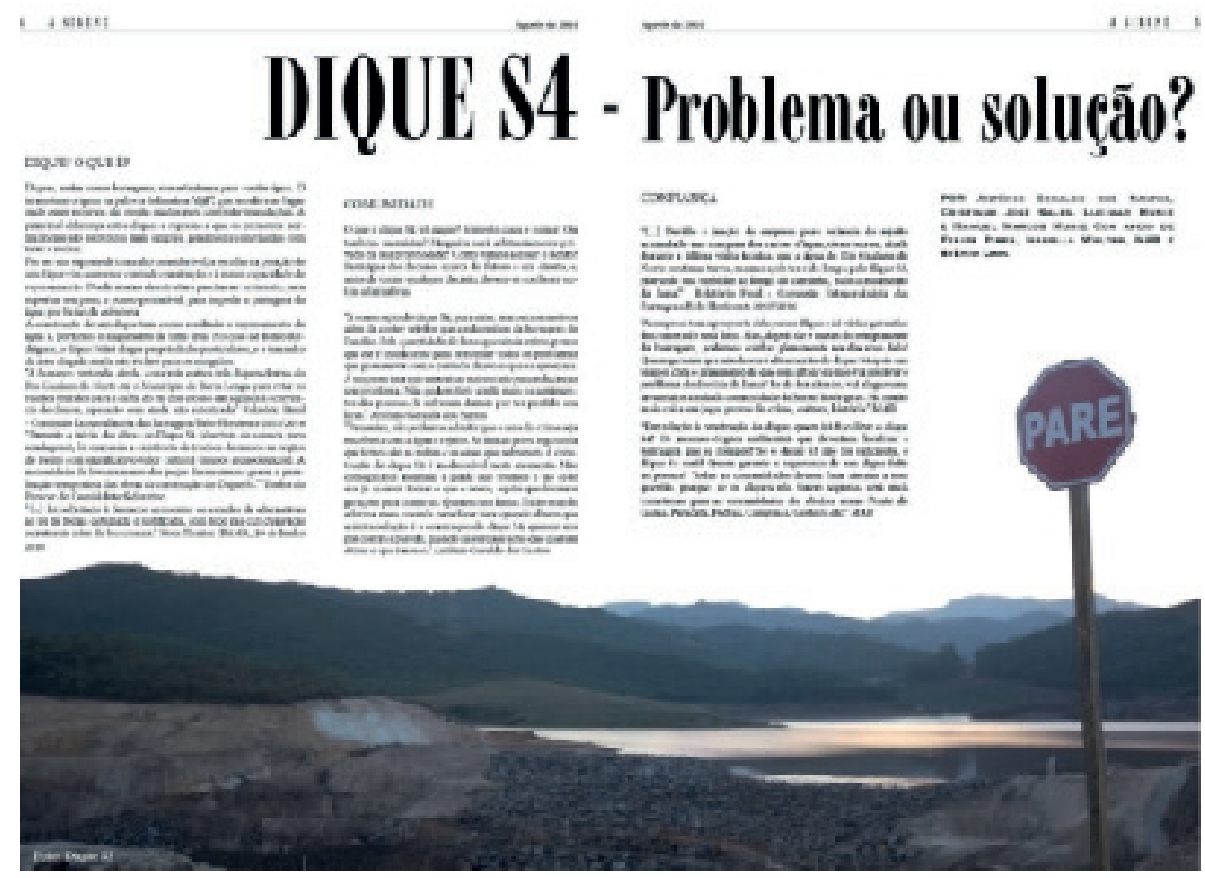


Nota-se que a própria fotografia utilizada lança mão do enquadramento para transmitir um sentido: a placa PARE, por mais que não tenha sido colocada no local com esse propósito, parece dizer, no contexto da foto, do sentimento dos sujeitos afetados pelo novo dique, ou seja: eles não querem que este sofrimento se repita. Este sofrimento também pode ser demonstrado com o texto-foto publicado na edição número 4 (figura 7). Nele, são expostos diversos desenhos e depoimentos de crianças que, mesmo sem saber exatamente as desastrosas consequências do ocorrido, estão em sofrimento pelas perdas causadas pela tragédia.

Figura 7: Acabou-se o que era doce, 2016, Edição 4 do Jornal A Sirene.
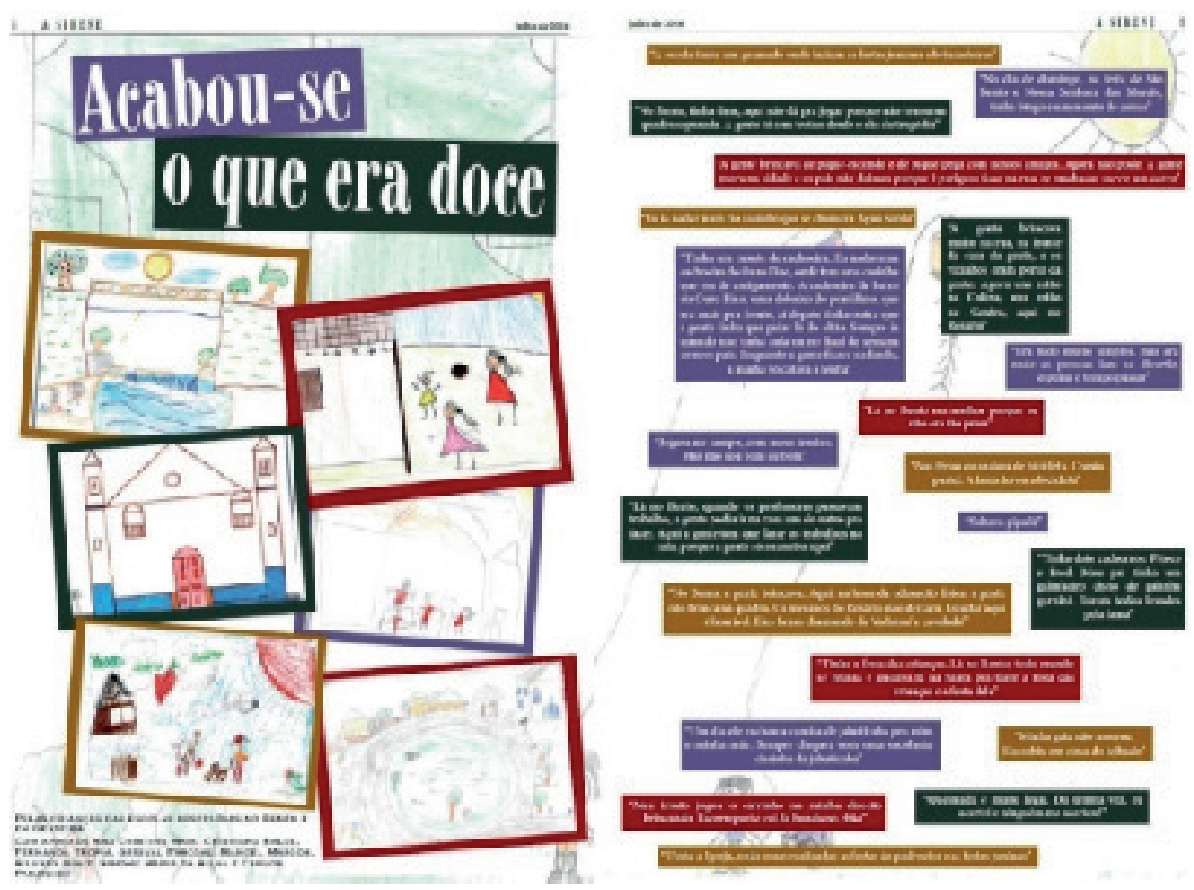

Neste mesmo sentido, $A$ Sirene mostra um rural que vive um trauma e está em sofrimento. Em primeiro lugar porque, no momento da tragédia, os sujeitos recorrem ao rural perdido para buscar explicações e projetarem uma espécie de memória coletiva aos outros sujeitos da região não atingidos em seus espaços de moradia. Mais do que perder 
um pedaço de terra ou um quintal, essas pessoas perderam as experiências vivenciadas naquele lugar. Novamente trazendo a reportagem intitulada "Um ano sem 'lá fora"' (figura 8), é evidente que os moradores das comunidades mostram a perda daquela realidade e como estão fazendo para contornar a situação. A imagem, que mostra um jardim vertical construído na cidade, ao mesmo tempo em que demonstra as alternativas para revisitar o rural perdido, traz a sensação de prisão com o uso da tela ao fundo, que separa a casa da natureza.

Figura 8: Um ano sem "lá fora", 2017, Edição 11 do Jornal A Sirene.

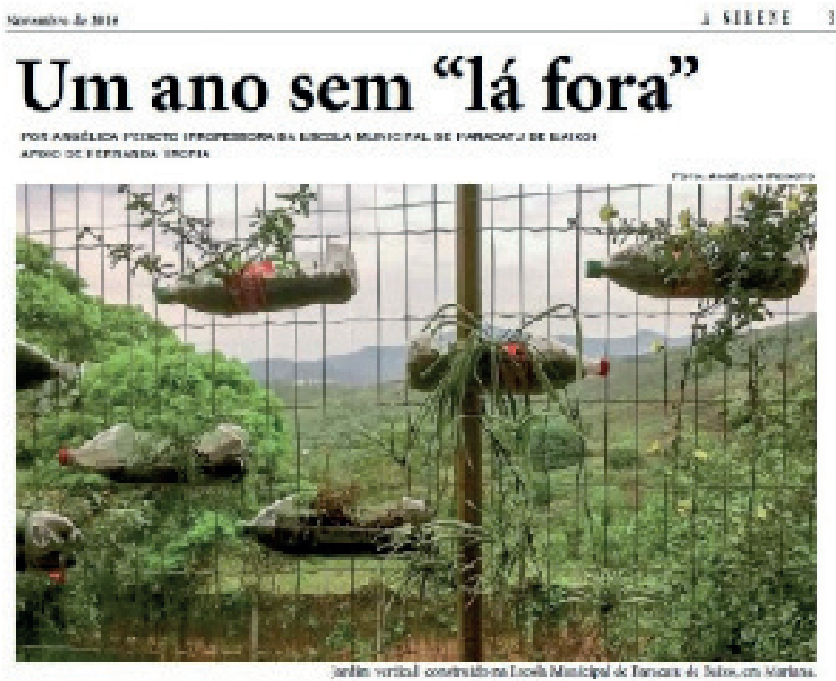

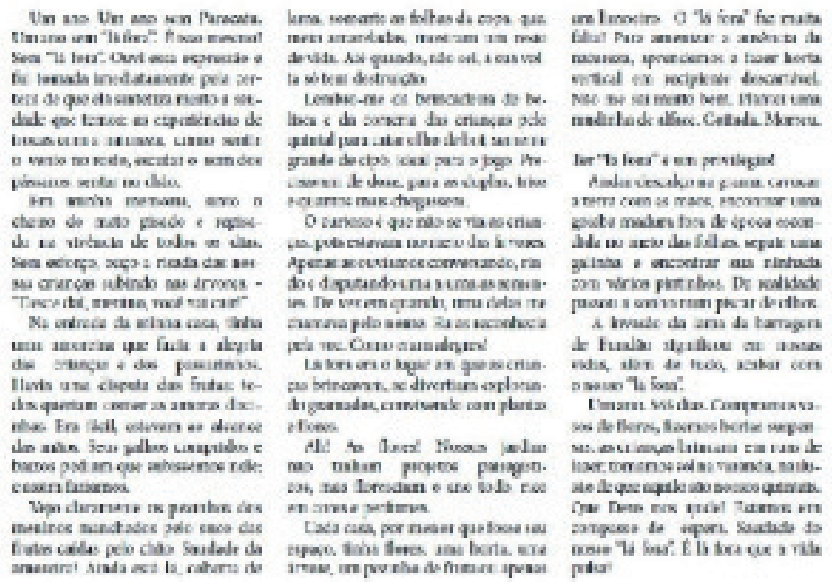


Além disso, é inegável perceber que o jornal mobiliza um rural que sofre enquanto natureza. Na edição número 5, uma reportagem com o título de "Quantas Isabellas não podem mais pescar?" (figura 9), evidencia o drama de um rio em meio ao qual peixes não crescem e pessoas não podem mais nadar. A imagem, ao fundo, evidencia uma área de floresta supostamente preservada e, mais à frente, um local que poderia ser utilizado para agricultura. Entretanto, chama atenção o rio marrom e toda lama em volta, reforçando ainda mais a ideia de um rural que sofre por fazer parte, de modo correlato, de uma natureza afetada.

Figura 9: Quantas Isabellas não podem mais pescar?, 2016, Edição 5 do Jornal A Sirene.

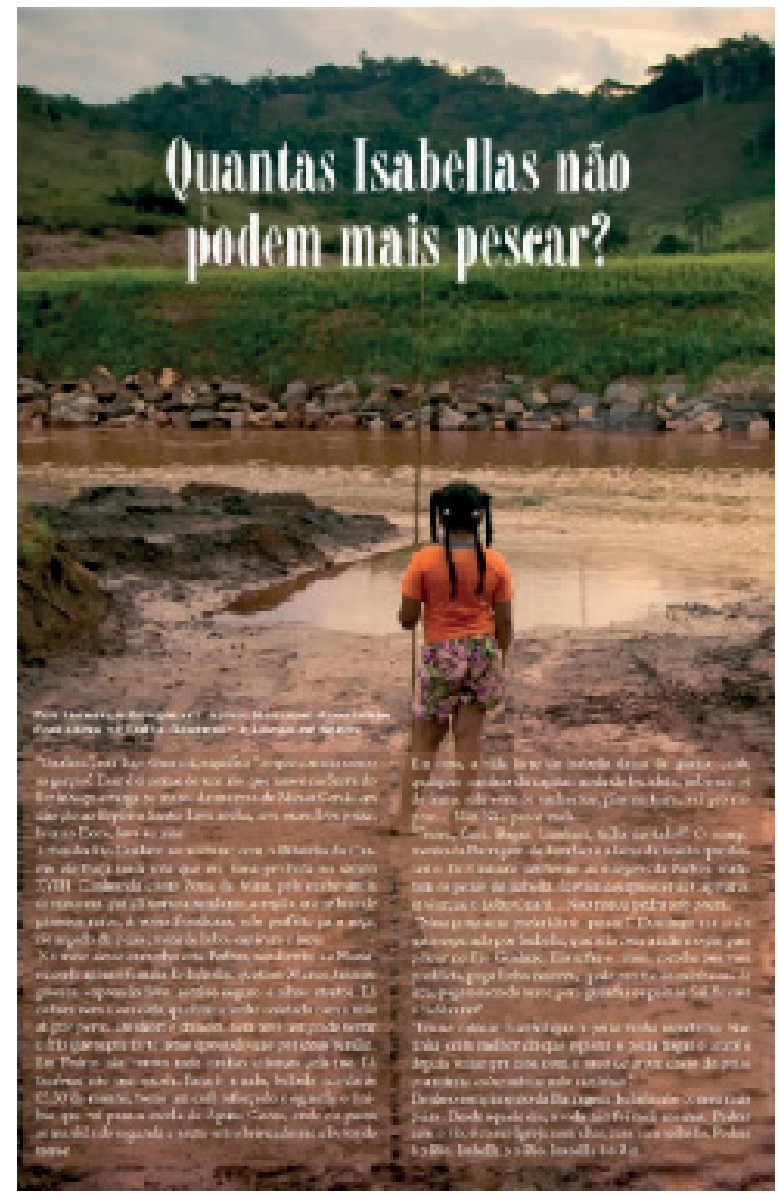


Neste contexto de dor e sofrimento, a identidade rural dos atingidos emerge na medida em que a mineração os afeta. É um rural em sofrimento que é provocado pelo trauma da mineração. Assim, ao mesmo tempo em que notamos que o rural não aparece problematizado pelos atingidos, há a busca por uma mineiridade supostamente perdida, junto a um hercúleo esforço por reconstrução de um lugar. Essa emergência do atingido, enquanto sujeito que agora passa a lutar pelos seus direitos, aparece na matéria "Aprender a ser atingido" da edição 8 (figura 10).

Figura 10: Aprender a ser atingido, 2016, Edição 8 do Jornal A Sirene.

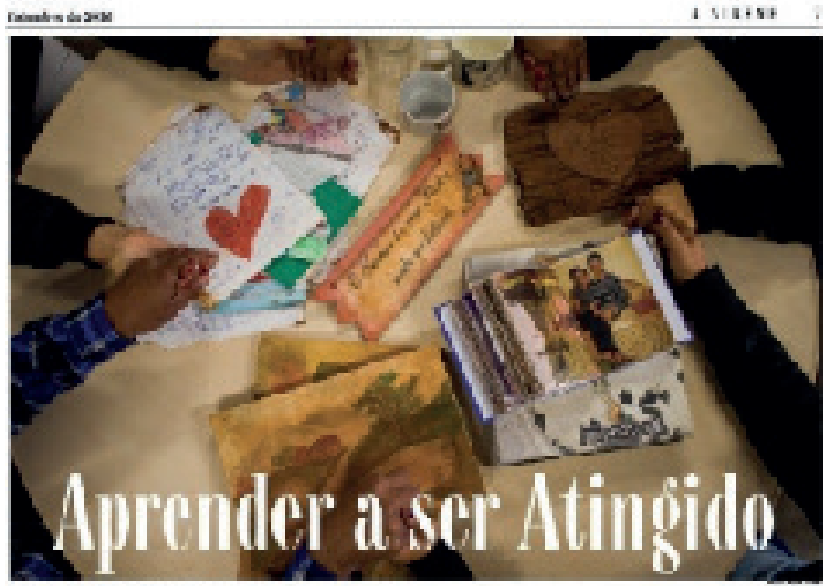

Hol ausn ma veroro

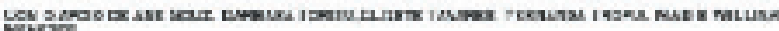

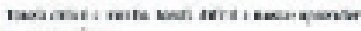
ase arevity.

Lend mive

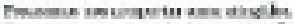

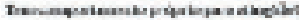

tanes

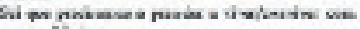

en rodisce

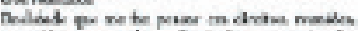

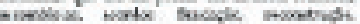

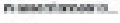

Cimontea qes ret Axsara anive. Onfudu yae Lifsu la e acesovide de polarere siapes wrve patir esigir, aeprcia:

leve certs trredo.

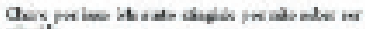
andilis

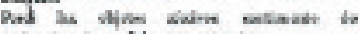

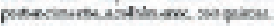

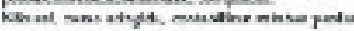
micposionti ven renta

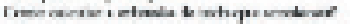

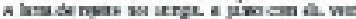

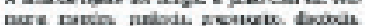

nie.

Xatk o kns.

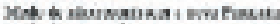

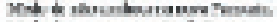

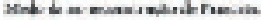

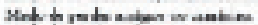

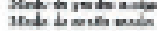

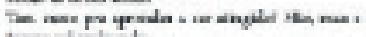

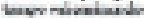

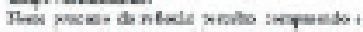

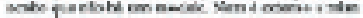

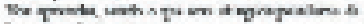
imion a are:

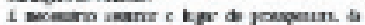

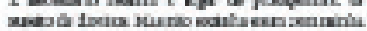

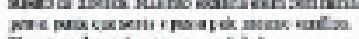

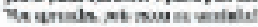

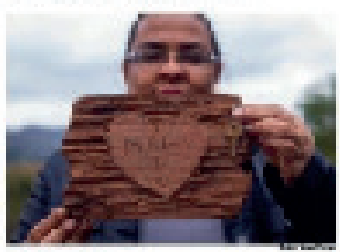


O ser atingido, neste caso, surge como um sujeito incompleto que tenta mesclar sua identidade e suas memórias com a nova condição imposta pelo sofrimento. Dessa forma, para ganhar forças perante o debate, recorre a elementos do seu passado que são fundantes de sua identidade de um presente e de um futuro projetado publicamente.

\section{Considerações finais}

Este texto teve como principal objetivo examinar as configurações de sentido entre mineração, mineiridade e ruralidade presentes no jornal A Sirene - publicação mensal elaborada na perspectiva dos sujeitos atingidos pela tragédia ambiental de Mariana (2015). De tal sorte, a partir da proposta metodológica de Abril (2012), buscamos analisar as narrativas jornalísticas de trauma e sofrimento presentes no jornal e como as mesmas evidenciam possíveis sentidos sobre um rural afetado pela mineração, nos contextos de Minas Gerais.

Foi possível evidenciar como o jornalismo de pequena escala, feito de modo, muitas vezes, subterrâneo e orquestrado por mídias alternativas, tem apresentado respostas significativas com relação à explicitação pública de traumas e sofrimentos, antecipando-se em relação a poderosas instituições da mídia - não apenas no que se refere à tempestividade da cobertura, mas à evidenciação de sua natureza jornalística sensibilizada pelo sofrimento. Como vimos, o jornal A Sirene mobiliza marcas de um trauma por meio da evidenciação de um rural supostamente perdido por estes sujeitos, assinalado por marcas identitárias de uma mineiridade historicamente forjada como estratégia discursiva de alívio de tensões e conflitos. Ao mobilizar este rural, o jornal (e os atingidos) acabam não problematizando essa identidade mineira como parte de um sofrimento originado de um complexo processo histórico, fruto da mineração.

Entretanto, ainda que o jogo discursivo de uma mineiridade consiga, de algum modo, se manter ainda escondido, o trauma experimentado pelos sujeitos evidencia a presença de um rural híbrido em sofrimento sofrimento este que não se refere somente às nefastas consequências da tragédia de Mariana, mas também ao processo histórico de emergência das localidades rurais afetadas, inseridas, desde que surgiram, 
no desigual e excludente processo de globalização.

Assim, o lugar dos atingidos parece se mostrar como um lugar de reivindicações históricas, de denúncia de estigmas, de produção de uma força política ao próprio grupo, que busca sobreviver em meio a um caos presente e às promessas de uma ruralidade tranquila, que eles mesmos pareciam não vivenciar em seu hibridismo sociohistoricamente posto. De tal sorte, se a própria mineiridade representa o lugar de acomodação histórica de conflitos, é a mesma mineiridade capaz de anunciar um sofrimento para além deles, insinuando a construção de uma pauta político-regional aos mineiros, numa urgente e desesperada tentativa de existirem e de resistirem a todo o sofrimento a eles imposto.

Por isso, cabe ressaltar uma instigante questão: ainda que o jornalismo não dê conta de explicitar o imbricado jogo discursivo entre mineiridade, mineração e ruralidade, é o próprio jornalismo que torna esse sofrimento explícito, a partir de uma evidência histórica da mineração e de um apelo ao recurso da explicitação de um trauma ambiental, que transcende as localidades, e que, em alguma medida, precisa ser repensado como algo próprio às bandas de Minas - nada pacatas, nada tranquilas, minas que escondem, em suas entranhas, um sofrimento de origem que necessita ser urgentemente expurgado e publicamente processado. 


\section{REFERÊNCIAS}

ABRIL, Gonzalo. Análisis crítico de textos visuales. Madrid: Editorial Sintesis, 2007.

ABRIL, Gonzalo. Tres dimensiones del texto y de la cultura visual. IC - Revista de Información y Comunicación, 2012, v.9, pp.15-35.

ÂNGELO, Marcel Henrique. Vozes das Montanhas: a representação do político mineiro em textos de Aécio Neves. Dissertação de mestrado. Programa de Pós-graduação em Letras da Universidade Federal de São João del-Rei, 2005.

BARBOSA, Karina Gomes; CARVALHO, André Luís. Narrativas do trauma no jornalismo local: o rompimento da barragem da Samarco em Mariana. Estudos em Jornalismo e Mídia, Florianópolis, v. 13, n. 2, p. 19-33, fev. 2017.

BRAGA, Gustavo Bastos; FIUZA, Ana Louise Carvalho, PINTO, Neide Maria Almeida. Padrões de consumo no campo: O modo de vida dos rurais brasileiros. Revista de Extensão e Estudos RuraisREVER, Viçosa, v. 4, n. 1, p. 56-73 jan./jun. 2015

CAL, Danila; LAGE; Leandro. Narrativas do sofrimento no jornalismo impresso: A construção de cenas e o lugar dos sujeitos. Brazilian Journalism Research -Volume 11 - Número 2- 2015.

CANCLINI, Néstor García. Consumidores e cidadãos: conflitos multiculturais da globalização. Rio de Janeiro: Ed. UFRJ, 1999.

CARNEIRO, Maria José. Ruralidade: novas identidades em construção. Estudos Sociedades e Agricultura, Rio de Janeiro: CPDA UFRRJ, n. 11, 1998.

DIAS, F. C. Mineiridade: construção e significado atual. Ciência e Trópico, Recife, v. 13, n. 1, p. 73 89, jan/jun. 1985.

FAUSTINO, Cristiane; FURTADO, Fabrina. Mineração e violações de direitos: o Projeto Ferro Carajás S11D, da Vale S.A. Relatório da Missão de investigação e incidência. Açailândia (MA). $1^{\mathrm{a}}$ edição, 2013.

FRANÇA, Vera Veiga. Jornalismo e vida social: a história amena de um jornal mineiro. Editora UFMG, Belo Horizonte, 1998

LEAL, Paulo Roberto Figueira; OLIVEIRA, Luiz Ademir de. A Disputa Pelo Sentido Da "Mineiridade": a construção da imagem de Aécio Neves na disputa presidencial de 2014. Revista Novos Olhares ? Vol.5 N.1 - Jan?Jun de 2016.

LYSARDO-DIAS, Dylia. Ethos e construção discursiva da identidade mineira. In: Encontro de Interação em Linguagem verbal e não-verbal, 2008, São Paulo. Anais do VIII ENIL. São Paulo: Editora da USP, 2008. V. 01. P;157-176

MAFRA, Rennan Lanna Martins. Vestígios da dengue no anúncio e no jornal: dimensões acontecimentais e formas de experiência pública na (da) cidade. Tese de doutorado. Pós-graduação em Comunicação -UFMG/FAFICH, Belo Horizonte, 2011. 366f.

MARTINS, Geraldo Inácio; SOUZA, Ângela Fagna Gomes. A Relação Campo e Cidade: Novas Urbanidades e Ruralidades, Definições e (Re) Definições. Caminhos de Geografia Uberlândia v. 11, n. 36 dez/2010 p. $37-51$. 
REIS, Liana Maria. Mineiridade: identidade regional e ideologia. Cadernos de História, Belo Horizonte, v. 9, n. 11, p. 89-98, jan. 2012.

ROCHA, S. M. Identidade regional, produção e recepção: a "mineiridade" na televisão. Semiosfera, Rio de Janeiro, v. 3, n. 4-5, abr./maio 2003.

RUA, João. A ressignificação do rural e as relações cidade-campo: uma contribuição geográfica. Revista da ANPEGE, Fortaleza, n. 2, ano 2, p. 45-66, 2005.

SILVA, Luiz Martins da. O jornalismo de trauma e o trauma do jornalismo. Panorama, Goiânia, v. 7, n. 1, p. 17-20, jan./jun. 2017.

SILVA, O. P. A mineração em minas gerais: passado, presente e futuro. Revista Geonomos 3(1), IGC-UFMG. Belo Horizonte, 1995.

TAVARES, Michele da Silva. Gonzalo Abril e o Texto Verbo-Visual: Uma Chave de Leitura Para o Jornalismo em Revista. In: Anais. XXXIX Congresso Brasileiro de Ciências da Comunicação, 2016, São Paulo / SP. XXXIX Congresso Brasileiro de Ciências da Comunicação, 2016.

VEIGA, J. E. Destinos da ruralidade no processo de globalização. Estudos Avançados 2004, Vol. 51, n. 18, pp. 51-67.

VIANNA, Graziela Mello. VAZ, Paulo Bernardo; SANTOS, Humberto. Sobre texto visual, som e imagem: novas paragens para as paisagens textuais. (In) COMPÓs- Associação Nacional dos Programas de Pós-Graduação em Comunicação, 2015. (online). Disponível em:<http://www.compos. org.br/biblioteca/compos-2015-99e14b33-2e1d-4278-8921-86937109f4a8 2896.pdf>. Acesso em: 18 de outubro de 2016.

Data de recebimento: 10 maio 2019

Data de aprovação: 13 setembro 2019 


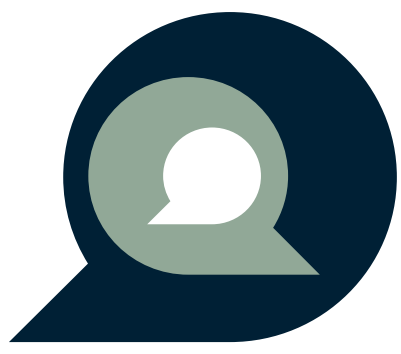

